\title{
Improving interdisciplinary collaboration in bio-economic modelling for agricultural systems
}

\author{
M.E. Kragt ${ }^{\text {a,b }}$, D.J. Pannella ${ }^{a}$ A. McVittiec, A.W. Stottc, B. Vosough Ahmadic, P. Wilson ${ }^{d}$ \\ ${ }^{a}$ Centre for Environmental Economics \& Policy, School of Agricultural \& Resource Economics, \\ University of Western Australia, Crawley WA 6009, Australia \\ ${ }^{b}$ CSIRO Agriculture Flagship, Floreat WA 6014, Australia \\ ' Scotland's Rural College (SRUC), Kings Buildings, West Mains Rd, Edinburgh, Midlothian EH9 3JG, UK \\ ${ }^{d}$ Rural Business Research Unit, Agricultural and Environmental Science, School of Biosciences, University \\ of Nottingham, Leicestershire LE12 5RD, UK
}

\section{Corresponding author}

Assist/Prof Marit E. Kragt

School of Agricultural and Resource Economics

University of Western Australia

M089 / 35 Stirling Highway

Crawley, WA 6009

Email=marit.kragt@uwa.edu.au

Phone $=+61(0) 864884653$

Acknowledgements: This paper is based on the outcomes of a workshop held at the Annual Conference of the Agricultural Economics Society, University of Warwick, 8-10 April 2013. The authors are grateful to the workshop attendees for their participation and comments. Kragt and Pannell were supported by funding from the Australian Research Council Centre of Excellence for Environmental Decisions. SRUC's authors were supported by the Scottish Government, under the Scottish Government Rural Affairs and the Environment Portfolio Strategic Research Programme 2011-2016, Theme 1: Ecosystem Services and Biodiversity and Theme 4: Economic Adaptation Wilson was in part supported by the Biotechnology and Biological Sciences Research Council (BBSRC) Sustainable Bioenergy Centre (BSBEC), under the programme for 'Lignocellulosic Conversion to Ethanol' (LACE) [Grant Ref: BB/G01616X/1]. This is an interdisciplinary project. The views expressed in this paper are those of the authors alone, and do not necessarily reflect the views of the collaborators or the policies of the funding bodies. 


\begin{abstract}
Interest in models that integrate biophysical and economic components of agri-environmental systems has increased, largely in recognition of the multiple services provided by agrienvironmental systems and reflecting the complexity of 'multi-functional' agriculture. We discuss the challenges of bio-economic modelling projects where biophysical and social-science research is integrated. Specific interdisciplinary challenges arise from, for example, differences in language and system understanding between disciplines, limited rewards for interdisciplinary research in the current academic merit system, and the time demands of interdisciplinary projects. Drawing on the authors' collective experiences in developing and applying bio-economic models, we discuss ways to overcome these challenges. Important lessons for future integrated modelling projects are to invest enough time at the start of the project to align research expectations, recognising the central role of communication, and training research 'integrators' who can facilitate collaboration within interdisciplinary teams.
\end{abstract}

Keywords: Interdisciplinary research; Integrated modelling; Bio-economics; Agricultural economics; Farm systems

JEL Classifications: Q51; Q57

\title{
Highlights
}

- Developing bio-economic models with interdisciplinary research teams faces many challenges

- We discuss key challenges such as cross-disciplinary communication, differences in types of data, and disparities in scales of analysis

- We also examine differences in publication strategies and academic merit for interdisciplinary research

- We suggest short-term practical solutions to improve interdisciplinary collaboration

- We propose that long-term 'system' changes will be needed to overcome integrated modelling challenges 


\section{Introduction}

An important feature of agricultural production systems is the interdependence of environmental, biological and socio-economic resources. Consequently, applied agricultural systems research will need to properly consider the relationships between the quality and quantity of natural resources - including soils, water, habitat quality, and plant and animal physiology, and farm production costs and profits (e.g. Hasler et al., 2003; Huber et al., 2013). . Addressing complex agri-environmental issues calls for interdisciplinary bio-economic research that recognises the complexity of agricultural systems, including their joint roles in food production, delivering ecosystem services, and contribution to rural economies. There is a growing interest in interdisciplinary bio-economic modelling, to provide information to policy makers and to help improve management decisions (Brouwer and Van Ittersum, 2010: 1).

There are several examples of projects that aimed to involve researchers from multiple disciplines. For example, interdisciplinary studies from the Rural Economy and Land Use (RELU) program (Lowe and Phillipson, 2006) included non-market valuation (Armsworth et al., 2012; Bateman et al., 2006), land use modelling (Arnoult et al., 2010) and food choice (Tiffin et al., 2006). Another example of an interdisciplinary project was the Economics and Welfare of Extensive Sheep (EWES) program (DEFRA, 2009). This project integrated measures of animal welfare into a bio-economic model that also included husbandry and socio-economic elements for extensively managed sheep flocks (Goddard, 2011; Stott et al., 2012). The EU funded SEAMLESS $^{1}$, SENSOR ${ }^{2}$, and LUPIS ${ }^{3}$ projects integrated biophysical, economic and social systems through research consortia that involved teams of researchers from different countries and a variety of disciplinary backgrounds (Brouwer and van Ittersum, 2010; Ewert et al., 2009; Helming et al, 2008; van Ittersum et al., 2008; Reidsma et al., 2011). The examples mentioned above necessarily involved interdisciplinary project teams, often working with stakeholders.

While the benefits of cross-disciplinary integration are widely acknowledged (Huber et al., 2013; Wam, 2010), it brings with it several important challenges. Rossini and Porter (1979) already

\footnotetext{
${ }^{1}$ Systems for Environmental and Agricultural Modelling; Linking European Science and Society

2 Tools for Environmental, Social and Economic Effects of Multifunctional Land Use in European Regions

${ }^{3}$ Land Use and Sustainable Development in Developing Countries
} 
noted that interdisciplinary research is often unsuccessful, and stressed the need for strategies that can successfully integrate knowledge from diverse disciplinary backgrounds. More than three decades later, Bruce et al. (2004) reviewed interdisciplinary projects that were carried out under the European Union Fifth Framework Directive. The authors found that "disappointingly few projects are clearly interdisciplinary, particularly in terms of crossing the boundary between natural and social sciences". These observations raise questions about the barriers to integration, and the best ways to conduct interdisciplinary research (Huber et al., 2013).

Rotmans and van Asselt (1996) noted some important challenges in interdisciplinary projects, such as the frequent lack of credibility in disciplinary science, the lack of common protocols and study approaches, and difficulties in balancing social, economic, and environmental considerations; these issues still remain (Beder, 2011). Differences in methodological approaches can also present a barrier to bio-economic research. For example, biophysical scientists typically rely on logical positivism, while economists often rely on principles of valuation and tradable commodities which may not yet be widely accepted by ecologists (Wam, 2010).

A large number of bio-economic models has been developed for different farming systems and agro-ecological conditions (e.g. Janssen and van Ittersum, 2007; Kragt et al., 2012). Such models may link biophysical and economic models, but their individual components are typically developed from a single-disciplinary perspective (e.g. economics or agronomy) (Kragt, 2012). Bioeconomic models tend to be limited in their level of integration, and often involve limited genuinely interdisciplinary teamwork (Hasler et al., 2003). There have been increasing calls for bio-economic models that focus more on integrating knowledge at conceptual as well as technical implementation levels (Flichman et al., 2011). This paper seeks to discuss how integrative bio-economic models can be developed in multi-disciplinary teams. We are motivated by the increasing collaboration between agronomists, economists, sociologists, and researchers from bio-physical science backgrounds in agro-environmental modelling projects. While research exists on interdisciplinary research (see, for example, Bammer, 2012; Brown et al, 2015; Kragt et al, 2013; van Rijnsoever and Hessels, 2011), there is limited focus on the integration of agricultural sciences and socio-economic research. Drawing on our collective experiences in applied agricultural economics, we will focus specifically on improving the success of bio- 
economic modelling projects that integrate natural sciences and economics in agricultural systems.

In the next section, we will discuss the main challenges related to working across economic and biophysical domains. In Section 3, we offer reflections on approaches that can help to overcome the identified challenges. The final section discusses the implications for research and training, specifically considering agricultural economics.

\section{Challenges to interdisciplinary research projects}

Literature discussing how to conduct interdisciplinary research in agricultural systems is relatively scarce. This section therefore draws from the wider literature on integrated research, and on the authors' experiences, to examine some of the key challenges that may be encountered in interdisciplinary research projects. The section is structured around six main issues: expectations, communication, data, resources, expertise and recognition. In Section 2, we explain these issues, followed by potential solutions in Section 3.

\subsection{Diverging expectations about the research objectives and model boundaries}

Bio-economic modelling that integrates economics with agricultural science, environmental science, ecology, epidemiology, or other sciences will bring together a range of participants. Such multi-disciplinary research teams bring specific management challenges that can pose major barriers to successful collaboration (Moxey and White, 1998). As with any research project, the expectations of team members may vary about what the research is going to address, the breadth and depth of the studies, and the methods of assessment. This can pose problems in interdisciplinary projects if each discipline has a different set of objectives and procedures. Expectations management is therefore an important component of working in teams, and is particularly challenging when working with multiple disciplinary expectations. 
To effectively and successfully develop interdisciplinary bio-economic models, team members need to reach agreement about the goals of the model, its scope, its scale, the research questions it will answer, etc. Without discussing team expectations and agreeing on the project objectives, there is a danger that individual researchers (a) embark on a collaborative project that does not align with their own objectives; or (b) pursue questions and conduct research that does not contribute to the joint goals for the bio-economic model. We have seen these issues reflected in the tendency for multi-disciplinary research projects to organise and manage work packages along disciplinary lines. In such cases, it is easy for work progress to become misaligned between work packages, even when overall objectives were initially agreed upon. Consequently, the overall project objectives may not be achieved, increasing the risk that team members will compensate by focusing on their individual disciplinary objectives (e.g. single-discipline publications).

An important distinction between many single- and multi-disciplinary studies and integrated research is the generally problem-oriented approach taken in bio-economic modelling. Bioeconomic models are often developed to answer real-world questions. These policy-relevant questions will provide the context for the analysis, and often guide the research procedures. In integrated research, contrary to most discipline-based and curiosity-driven inquiry, problems designate methods and scope, not the reverse (Brewer, 1999). Researchers embarking on an interdisciplinary project need to be aware of this difference when setting expectations about project outcomes.

\subsection{Difficulties in communication between disciplines}

Many authors have noted the difficulties in communicating science across disciplines (e.g.Brown et al, 2015; Kragt et al., 2011), and this remains a challenge in bio-economic modelling projects. Communication difficulties can arise for various reasons. Firstly, disciplines have their own specific jargon - which may not be understood by other disciplines. Disciplinary jargon 
complicates discussion between team members of different disciplines, particularly at early project stages when team members are still unfamiliar with each other. Improving communication does not necessarily mean that participants need to agree upon "a common language" (Tress et al., 2007). Overcoming language difficulties is a matter of reducing the use of jargon, and agreeing on a common understanding of terminology from the outset.

Each discipline's way of thinking and communicating is shaped by different assumptions about the world, captured in part by disciplinary epistemology and ontologies ${ }^{4}$ (Wam, 2010). Both of these tend to be bound by disciplinary norms. This means that disciplines have different ways to define and express knowledge - which may not be valued by other disciplines.

Norgaard (1992) noted that each discipline has its own 'cultural' belief system: a largely unstated, unquestioned system of beliefs held in common. This means that disciplinary 'beliefs' may not always be fully compatible, which will present barriers to communication and effective collaboration. In an interdisciplinary modelling project, researchers must actively resist the tendency to assume that one's own view of the world is universally shared.

Another important difference between disciplines involves publication strategies. For example, perspectives may differ about the 'status' of peer-reviewed journal publications (Sciences) versus books or book chapters (Humanities) (Huang and Chang, 2008). We have seen contrasts between applied science journals and 'prestigious' economics journals. The latter tend to seek theoretical or methodological innovation ahead of practically useful applied information. This leads to a potential publication bias against robust applications of accepted research approaches, as might be used in interdisciplinary systems research. Further, many journals are likely to use singledisciplinary peer reviewers whose subject-specific expectations when scrutinising interdisciplinary manuscripts may not always appreciate the complexities and innovations involved in interdisciplinary research (Harvey, 2006).

\footnotetext{
${ }^{4}$ Epistemology deals with our beliefs about knowledge: what we can know, how we can know it, as well as our values and aims; ontologies relate to the kind of things that exist; our world views and assumptions about the nature of things (Grix, 2002). In Artificial Intelligence, ontologies refer to a set of concepts that are specified in some way to create an agreed-upon vocabulary for exchanging information.
} 
Arrangements for co-authorship and criteria of choosing scientific journals may substantially vary between disciplines. For example, in the biophysical sciences it is regular practice to publish papers with many co-authors, while in economics most papers have between one and three coauthors. Citation and referencing patterns also vary noticeably by academic disciplines (Perry, 2012). Publications in science journals tend to be more highly cited, partly because papers in biophysical and physical sciences have much longer reference lists than those in economics journals (Perry, 2012). While this may be beneficial for interdisciplinary research published in science journals, it leads to marked differences in journal impact factors, which confounds comparison of publications in science versus economics journals. Despite the availability of alternative impact metrics and research assessments that rely less on journal impact factors (see Section 3.5 below), impact factors remain hegemonic.

Finally, there may be a key distinction in the extent to which different disciplines communicate about their research prior to having their studies peer-reviewed and published. The outcomes of much interdisciplinary research will often be published in grey literature first (e.g. reports or policy briefs), due to its applied nature and closeness to policy needs. While modellers may be relatively comfortable presenting 'work in progress' to their peers, some other sciences are more reluctant to reveal preliminary findings in non-reviewed literature because of competition concerns.

\subsection{Differences in scales of inquiry and data requirements}

Agricultural systems modelling has to deal with analyses at field, farm, regional and larger functional scales (Ewert et al., 2011). A barrier lies in the fundamentally different levels of inquiry associated with research that spans multiple spatial and temporal scales (Volk and Ewert, 2011). This has implications in terms of theory and empirical data. Agronomy, ecology, economics, epidemiology, engineering, hydrology, etc. are all driven by their disciplinary knowledge domains, which leads to differences in systems thinking, and different scales of analysis. For example, where hydrologists may analyse daily or even hourly time steps, crop modellers may examine processes at annual or seasonal time frames. Spatial scales also vary. Plant or animal 
physiologists may study processes at the scale of an individual crop/animal or a square metre, and ecologists may focus on ecosystem processes at a larger landscape scale, which may, or may not, overlap with the field, farm, or administrative boundaries of interest to policy makers. Ensuring consistency across scales of inquiry between disciplines, and the linking models across scales (scaling methods) are major challenges in integrated modelling (Ewert et al, 2011; Weersink et al., 2002).

An important issue that is easily overlooked in interdisciplinary research is the different attitudes

of disciplines towards different types of data (e.g. qualitative or quantitative). Disciplinary traditions will influence methodological preferences, standards of assessment, and even the value placed on different types of knowledge and data. For example, sociologists may use forms of tacit or historical knowledge (often in qualitative form) that are less valued by biophysical scientists who tend to prefer quantitative data. Interdisciplinary research needs to use processes that can accommodate varying types of knowledge and manage the ways in which such knowledge is organised (Kragt et al., 2013). Approaches such as Bayesian networks offer the opportunity to co-construct models using different types of knowledge and data (Wang et al, 2009). We discuss these in more detail in Section 3.3 below.

\subsection{Limitation of necessary resources}

The coordination of projects involving researchers from different disciplines will generally demand considerable time, money, and other resources (Brown et al, 2015). Participants in interdisciplinary research must first come together to agree on the relevant problem under consideration, define common objectives, characterise expectations, establish a common understanding of the research issue, and develop data handling procedures that are accepted by all participants. Indeed, Tress et al. (2007) found that time demands was one of the greatest barriers to integration of disciplines. Nooteboom (2000) also pointed out that transaction costs for interdisciplinary collaborations are higher than for 'regular' (single-) disciplinary collaborations due to the cognitive distance between the parties involved. Bateman et al. (2006) 
note the benefits of building upon previous collaboration in interdisciplinary projects, thereby avoiding fixed costs of establishing new collaborative relationships.

\subsection{Few experienced integrators}

Jakobsen and McLaughlin (2004) and Kragt et al. (2013) emphasised the importance of experienced facilitators in interdisciplinary projects. This requires more than communication skills. Nooteboom (2000) advocates a third party to play the role of go-between to facilitate communication. However, the reality of scientific cultures, where peer acceptance and respect are crucial, implies that expert colleagues are likely to be more successful integrators than thirdparty facilitators.

Compared to working alone or in relatively homogeneous groups, managing interdisciplinary research requires more social, managerial, and communication skills. Scientists may not be inclined or equipped, by training or personal capabilities, to invest time or energy in these activities (Klijn, 2003). Because the research sector does not always reward management experience of scientists (König et al., 2013), there is a shortage of integrators with practical management experiences in interdisciplinary projects.

Further, in most university degrees, there is little emphasis or training in how to conduct interdisciplinary research. Much university teaching and graduate student research has remained largely structured around individual disciplines (Klein, 2004; Nutbeam, 2013), although there is increasing recognition for the need to adopt more interdisciplinary graduate training in the agricultural, economic and social sciences (Haapasaari et al., 2012). While there are certainly universities that teach interdisciplinary subjects, there is limited focus on developing the practical research techniques needed to collaborate successfully in interdisciplinary teams, such as communication and facilitation skills.

\subsection{Limited recognition for interdisciplinary work}


Numerous authors have pointed to the barriers that current academic merit systems present to interdisciplinary research (Klijn, 2003; Ledford, 2015; Moxey and White, 1998; Tress et al., 2003). Traditional academic systems for hiring, tenure, promotion, status, and recognition are usually controlled by departments with single-disciplinary structures. Faculty members who undertake research or teach in interdisciplinary teams may receive less departmental credit than those who work within single disciplines (CFIR, 2004). Furthermore, university rankings, which are increasingly important to higher education, are primarily driven by single-disciplinary excellence. Rafols et al. (2012) found that 'excellence-based' journal rankings show systematic bias in favour of single-discipline research. They conclude that interdisciplinary research will be suppressed if journal rankings determine esteem and resources. Having journals tailored to disciplinary approaches limits the opportunities to publish peer-reviewed interdisciplinary research. Not only are there still relatively few international journals that target multi-disciplinary research, but the refereeing process for articles and research bids often leads to the persistence of disciplinary silos against perceived "disciplinary dilution" (Moxey and White, 1998).

\section{Lessons for integrated bio-economic modelling}

In the previous section, we outlined numerous challenges to working in interdisciplinary teams. While there are many studies on interdisciplinary research that stress the challenges to working across disciplines (Britz et al., 2012; Harris, 2002; Kragt, 2012; Moxey and White, 1998), guidelines to improve the integration process are rarely provided. ${ }^{5}$ Responding to the challenges described in Section 2, we provide six lessons that can contribute to more successful organisation and execution of interdisciplinary bio-economic projects (see also Box 1).

[INSERT BOX 1 ABOUT HERE]

\footnotetext{
${ }^{5}$ Interesting experiences with interdisciplinary research can be found in, for example, Haapasaari et al. (2012) and Klijn (2003)
} 


\subsection{Lesson 1: Invest time at the start of the project to align expectations}

Project proposal writing is typically under-resourced in terms of staff cost and time requirements; it is also often difficult to ensure sufficient engagement from all project partners at this stage. Although these issues are common to all research proposals, we suggest that they cause particular problems in interdisciplinary contexts where time is needed to develop joint understanding of research questions, concepts and expectations (Section 2.4). In practical terms, integrated research proposals will need to consider that research schedules and milestones may take longer to meet than simply the sum of disciplinary tasks (e.g. because of time needed to develop models or the sequencing of research activities).

Once funded, in a desire to get the project underway, research projects may commence without sufficient communication and coordination between project participants about the aims, objectives, and research procedures. We suggest that projects should commence with an inception meeting in which the project team endeavours to: agree on the nature and structure of the system under consideration (for example, by developing a conceptual model of the system - Kragt et al., 2013); clarify the modelling objectives and agree on common research questions; decide on a common scale of analysis; reach understanding about discipline-specific terms and concepts; and establish research procedures that are accepted by all participants. Ultimately, the answers to these should be driven by the research question; if favoured models and approaches are incompatible with that question then these should be reconsidered and/or the research question reframed. Team members need to reach consensus about the model's boundaries, scope and intended capabilities, and about what can be delivered at the end of the project. Issues of data integration and appropriate units of analyses need to be understood and agreed at the outset (Bateman et al., 2006). Spending sufficient time at the start of the project can avoid unrealistic expectations, as well as problems with data or modelling incompatibilities. It is equally important to involve research sponsors at this stage, as not all stakeholders may have a full understanding of the complexities involved in an interdisciplinary project. Researchers need to ensure that the promised output is based on realistic expectations, and address any concerns that research funders or other stakeholders may have at the outset. 
Negotiations during the proposal and inception phases can also prevent too much focus on discipline-specific interests rather than the overall goal of the bio-economic modelling exercise. Academics may have a tendency to focus on research questions that address discipline-specific challenges, which can divert effort from the integration process. Participants in an integrated agricultural modelling project need to develop an understanding of each other's perspectives, so that disciplinary approaches are mutually respected. An inception meeting provides a valuable opportunity for aligning expectations and to improve team support for the overall goal of developing an integrated model. Mutual understanding and 'rules-of-the-game' need to be established at the outset. Involving all project participants explicitly from the start is likely to increase team members' 'ownership' of the project, and increase participants' commitment to delivering the integrated modelling outputs. Key to this is the active participation by team members throughout the proposal and inception phases rather than passive processes dominated by project or disciplinary leaders. The difficulties in achieving such participation should not be underestimated-they require adequate resources and time which may not be available during proposal stages. Funders of integrated research may need to provide capacity building funding to facilitate interdisciplinary project development.

\subsection{Lesson 2: Communication is crucial}

Effective communication is essential to the success of lesson 1. An approach to achieving this is to invite team members to regularly present their expectations, existing research, or conceptual models during project meetings. Such discussions present an opportunity to clarify disciplinary language and uncover differences in understanding. At one of the early meetings, it is useful to ensure that terminology and definitions are consistent with those used by research funders and/or anticipated model users. In particular, the use of discipline-specific jargon will complicate communication between disciplines. For example, economic terms such as 'marginal benefit', 'opportunity cost' or 'discount rate' are likely to be unfamiliar to some biological or physical scientists. Reducing the use of jargon, and creating an open, collegial atmosphere where team

members can give feedback to check understanding is an essential routine for effective communication in interdisciplinary research teams, but it requires courage to acknowledge that 
one may lack understanding of other disciplines (Haapasaari et al., 2012). Clarifying terminology at the start of the project will save time and effort later on, and will facilitate effective communication between individuals from different disciplines by avoiding misinterpretation of particular terms, techniques, outcomes or uncertainties (see Box 2 for a case study example). A set of terms may be agreed upon by developing a shared ontology; such as a thesaurus, a glossary of terms, conceptual diagrams, mind maps, or semantic modelling. Ontologies were used in the SEAMLESS modelling project to more consistently and transparently define scenarios (Janssen et al, 2009b) and to facilitate the linkage of model components (van Ittersum, 2009). Developing a shared ontology can help to define concepts, organise the necessary shared conceptualisation and so facilitate interdisciplinary research.

In our experience, successful communication requires active, rather than passive, approaches with regular workshops and meetings at each stage of the project to check on and agree further progress. These are preferable to email and teleconferencing, although advances in video and web-conferencing can at least in part overcome the resource and time requirements of physical meetings. The use of collaborative technology can also help to achieve regular and consistent communication. For example, sharing of ontologies and other information can be facilitated through media platforms such as Microsoft and Google cloud sharing platforms, DropBox, GroupWikis, etc.

It is surprising how often basic tenets of effective communication are neglected by research project teams. A simple model of communication that emphasises feedback and beneficial change rather than just the transmission of a message underpins successful management of all teams (Williams, 1996). For interdisciplinary teams, it is particularly important to seek feedback to establish whether mutual understanding has been achieved or whether further communication is necessary (Haapasaari et al., 2012).

Visual communication of ideas can be another approach to overcome language differences. Visual aids can include clearly labelled and explained graphs and tables, maps, conceptual diagrams, mental mapping, infographics, etc. The brain can generally process images more easily than text. Therefore, visual aids can facilitate the communication process by making information from different disciplinary sources explicit and debatable. As with verbal and written 
communication, the use of visual aids should be active rather than passive. For example, conceptual diagrams can be co-constructed or, where pre-existing, deconstructed as a means of exploring and developing joint understanding.

Visualisation offers potential for creating new knowledge in interdisciplinary research teams. Visual aids can, unlike text, quickly be revised (if they are not too complex), supporting the rapid and joint improvement of new ideas (Eppler and Burkhard, 2007). Of course, many different visual aids are available. Which tool is best to use will depend on the particular circumstances and experiences of the interdisciplinary project team.

[INSERT BOX 2 ABOUT HERE]

\subsection{Lesson 3: Develop and share data-handling and research protocols}

Scientists and economists ask different questions (Section 2.3) and therefore collect different data. Biophysical scientists typically perform quantitative research with a positive focus on investigating the state of a system: "If this happens, what would be the state of the system?". Economics, on the other hand, may use qualitative or interpretive validation approaches (Brown et al, 2015). The data collected in applied economics research can be very different from biophysical data (e.g. the analysis of marginal changes versus biophysical analysis of the state of a system). Furthermore, much economics work is normative rather than positive; concerned with improving current conditions (Janssen and van Ittersum, 2007) or finding an optimal outcome. An integrated bio-economic model needs, in the first instance, to find ways to connect different levels of analysis and-consequently- different types of data (Ewert et al, 2011; Kragt et al., 2013). Differences in systems thinking are likely to be one cause of data incompatibilities. Up-front communication, team-building, developing conceptual frameworks and shared collaborative ontologies (Janssen et al, 2009a) can help ensure that data are available in the format, location, and appropriate context needed for use by other disciplines, and can foster understanding of how other disciplines measure system processes. 
Because representative data based on scientific evidence will not always be available, many interdisciplinary projects rely on expert judgements to fill the inevitable data gaps. However, not all experts are willing and able to express their judgements in the absence of full information. Strategies for eliciting expert knowledge under uncertainty include the Delphi method (Tanure et al., 2013), scenario analyses (Canavese et al., 2014), and other methods (see, for examples, Aspinall, 2010; Burgman et al., 2006; Murray et al., 2009). Given that, in many cases, expert judgements provide a key input into bio-economic modelling, the interdisciplinary team would benefit from researchers with experience in knowledge elicitation processes (i.e. a 'knowledge broker'). To effectively elicit the relevant disciplinary information, this knowledge broker will typically need to have some technical knowledge about the environmental and biological systems that are included in the model. Applied economists, with appropriate training and experience, can play a leading role as a knowledge broker, as long as they are willing and able to learn about the technical data requirements of the biophysical models. This will greatly facilitate effective conversations with technical scientists involved in the project.

\subsection{Lesson 4: Train research 'integrators'}

Setting up and managing interdisciplinary research teams is by no means an easy task. Bringing together different disciplinary insights to provide answers to a real-world problem requires researchers to have particular skills (McDonald et al., 2009). Research 'integrators' are experts who appreciate different epistemologies and can bring together multi-disciplinary knowledge.

Ideally, an integrator should have a broad understanding of the various biophysical and social sciences involved in the project, and should recognise the different underlying values that give rise to disciplinary research approaches. Unfortunately, there are relatively few researchers with the skills and expertise to identify, collect, and synthesise diverse information in ways that unite the disciplines involved. In addition to multi-disciplinary understanding, integrators need to have the management and communication skills to make an interdisciplinary team work. In economics, the lack of integrators arises from two things: (1) The lack of academic recognition for integration skills (discussed in the next Section); and (2) The focus of much 'pure' economic 
research training on disciplinary approaches. This is despite economics being viewed as the lead social science discipline to integrate with the natural sciences, because of its focus on decision making, and because its quantitative methods can facilitate engagement with technical and biological sciences (Lowe and Phillipson, 2006).

Most universities, built around disciplinary departments, provide under- and postgraduate students with little training in conducting interdisciplinary research. While curricula exist that are taught across disciplines, there is much less emphasis on developing the research skills necessary for successful interdisciplinary projects. We therefore advocate including 'integration modules' in the university curriculum. These can take the form of, for example, summer schools to teach interdisciplinary research skills including communication, meeting management, facilitation, bioeconomic modelling, elicitation of information from experts, development of integrative conceptual frameworks, and so on. In such modules, the capabilities and applications of integrated modelling to address interesting research questions should be demonstrated and highlighted to students and early-career researchers to promote the benefits of interdisciplinary research projects. It should also be possible to facilitate student projects that involve collaboration with students from other disciplines. Institutions play a role here by enabling interdisciplinary PhD-programs where supervisors can come from different department or faculties (such as, e.g., the Interdisciplinary Graduate School at Singapore's Nanyang Technological University).

Successful senior integrators can act as role models; conference organisers can include workshops, presentations, or key note speakers dealing with interdisciplinary research; departmental seminar convenors can organise interdisciplinary seminars that expose students to multi-disciplinary knowledge. For example, the authors of this paper have delivered bioeconomic modelling seminars at science faculties and participated in interdisciplinary conferences (such as those of the International Environmental Modelling and Software Society).

\subsection{Lesson 5: Recognise the benefits of interdisciplinary research}


The existing academic merit system presents significant disincentives to interdisciplinary researchers. The top-tier journals in agricultural, environmental and resource economics (e.g. the Journal of Environmental Economics and Management and the American Journal of Agricultural Economics) emphasise theoretical rigour and publish almost no interdisciplinary bio-economic research. Departmental reward structures are often based on single-discipline research excellence and publications in high-impact economics journals, providing little incentive for academics to undertake interdisciplinary projects. Despite this academic bias towards more conventional, disciplinary approaches (Brown et al., 2015), we believe that there are considerable benefits of interdisciplinary modelling projects. It is our experience that such projects can result in higher citation rates for our disciplinary publications and in many coauthored joint publications. In addition to discipline-specific papers written on our component of the project, synthesis papers about the overall research can be published in highly cited journals (e.g. the recent Nature special issue on Interdisciplinarity; nature.com/inter). However, it can be difficult to publish joint interdisciplinary research in economics journals, and it can sometimes take several years to start publishing joint papers (Brown et al., 2015).

Countering the current dominance of single-discipline research will require a modification of academic reward structures. Research excellence in multi- and interdisciplinary fields will need to be reflected in hiring, tenure, and promotion practices. To some extent this is being addressed with greater emphasis on research impacts and outcomes. For example, the UK's Research Excellence Framework reflects an interest in assessing value-for-money from public research funding and may favour more applied and interdisciplinary research. Other examples include the European Union funded SIAMPI project ${ }^{6}$ and the STAR-METRICS project ${ }^{7}$ in the US, which aimed to assess the social impacts of government-funded research projects.

\footnotetext{
${ }^{6}$ Social Impact Assessment Methods for research and funding instruments through the study of Productive Interactions between science and society

${ }^{7}$ Science and Technology for America's Reinvestment Measuring the EffecTs of Research on Innovation, Competitiveness and Science
} 
Academic societies and international associations could also play an important role. They could establish prizes for exemplary integrated research ${ }^{8}$, and change the editorial policies of their journals to encourage greater acceptance of high-quality inter-disciplinary research.

\subsection{Lesson 6: Follow the money}

It is worth recognising that there already exist incentives to engage in interdisciplinary research. The need for integration is increasingly recognised by policymakers and research funders, who acknowledge that single-discipline projects are typically insufficient to meet policy needs on key issues such as climate change and agriculture (see, for example, Moran et al., 2011).

Recent UK Research Council programmes such as the Valuing Nature Network (VNN), Biodiversity and Ecosystem Service Sustainability $(B E S S)^{9}$ and Rural Economy and Land Use (RELU) have required interdisciplinary consortia. The US National Institutes of Health aims to stimulated collaboration and multidisciplinary research by allowing multiple principal investigators on what had previously been purely single-investigator grants. In Australia, research funding programs such as the Cooperative Research Centres (CRCs), the National Environmental Science Programme (NESP), and the Australian Research Council's Centre of Excellence Programme also emphasise and support multi-disciplinary research. Hence, although increasing funding does not remove all of the barriers to interdisciplinary research, it should act as an important market signal to the research community.

\section{Conclusion}

Policy makers are increasingly faced with complex problems involving decisions across what were previously separate policy (and disciplinary) silos. Consequently, decision support needs to be based on integrated models that are underpinned by appropriate interdisciplinary research. However, a major constraint is the development of sufficiently effective interdisciplinary

\footnotetext{
${ }^{8}$ See, for example, http://www.aares.org.au/AARES/Honours_and_Awards/Communications_Award.aspx

${ }^{9}$ See http://www.valuing-nature.net/ and http://www.nerc-bess.net/
} 
research teams. This paper addressed this problem, discussing barriers to progress, and suggesting ways in which they can be overcome.

Integrated bio-economic models are useful to support policy decisions about agri-environmental systems. Developing such models in interdisciplinary teams poses considerable challenges to the participants involved. Challenges arise from differences in terminology, entrenched academic territories, incompatible data and methodological differences, limited experience with interdisciplinary research, and the lack of recognition in the academic merit system. However, the increased emphasis on funding for interdisciplinary research combined with the research positioning of agricultural and applied economics, arguably places the subject at the centre of the debate about policy-relevant interdisciplinary research.

We offer advice that can help improve interdisciplinary research collaboration in bio-economic modelling projects. During the development and initial stages of the study, it is vital to align researchers' expectations about the scope and resource needs of the project. Agreeing on research objectives and terminology at the start will help to collaborate more effectively during the project. This can be aided by visual aids, glossaries of terms, conceptual models etc. Next to research objectives, and establishing a common understanding of the terms used during the project, interdisciplinary research teams are encouraged to develop shared research protocols and data-handling processes. This can avoid differences across disciplines in the types of data collected and the way in which they are analysed.

In addition to the practical recommendations above, there is a need for long-term cultural and institutional shifts that facilitate interdisciplinary research. The need to train research 'integrators', who have the necessary management and communication skills to manage interdisciplinary projects, can commence in our undergraduate degrees. There is a role for senior researchers to present integrated bio-economics work to their students and ECRs, as well as at conferences outside their own disciplinary field. Increasing grant-winning opportunities and the potentially high impact of research findings are obvious motivators. More subtle are the opportunities for insights within the home discipline that might be gained from collaboration with other disciplines perhaps by questioning accepted dogma or providing new ways of looking at old problems (e.g. Mclnerney, 1996). 
While the need and advantages of integrated research and bio-economic modelling is increasingly acknowledged by policy makers and research funders, there is still little academic recognition for interdisciplinary researchers. There is a role for institutions to support interdisciplinary research by, for example, introducing key performance indicators that reward research collaboration. Funders may place a greater emphasis on research impact and outcomes (in addition to outputs) as a way to promote interdisciplinary research. Applied agricultural systems research is in an excellent position to demonstrate the real-world impacts of interdisciplinary projects, as well as the knowledge development that occurs in multi-disciplinary teams, to increase recognition for interdisciplinary research outputs.

\section{References}

Armsworth, P.R., Acs, S., Dallimer, M., Gaston, K.J., Hanley, N., Wilson, P., 2012. The cost of policy simplification in conservation incentive programs. Ecol. Lett. 15, 406-414.

Arnoult, M.H., Jones, P.J., Tranter, R.B., Tiffin, R., Traill, W.B., Tzanopoulos, J., 2010. Modelling the likely impact of healthy eating guidelines on agricultural production and land use in England and Wales. Land Use Policy 27, 1046-1055.

Aspinall, W., 2010. A route to more tractable expert advice. Nature 463, 294-295.

Bammer, G., 2012. Strengthening Interdisciplinary Research: What it is, what it does, how it does it and how it is supported. Report for the Australian Council of Learned Academies. url: www.acola.org.au.

Bateman, I.J., Brouwer, R., Davies, H., Day, B.H., Deflandre, A., DiFalco, S., Georgiou, S., Hadley, D., Hutchins, M., Jones, A.P., Kay, D., Leeks, G., Lewis, M., Lovett, A.A., Neal, C., Posen, P., Rigby, D., Turner, R.K., 2006. Analysing the Agricultural Costs and Non-market Benefits of Implementing the Water Framework Directive. J. Agric. Econ. 57, 221-237.

Beder, S., 2011. Environmental economics and ecological economics: the contribution of interdisciplinarity to understanding, influence and effectiveness. Environmental Conservation $38,140-150$.

Brewer, G.D., 1999. The challenges of interdisciplinarity. Policy Sci. 32, 327-337.

Britz, W., van Ittersum, M., Oude Lansink, A., Heckelei, T., 2012. Tools for Integrated Assessment in Agriculture. State of the Art and Challenges. 
Brouwer, F.M., Van Ittersum, M., 2010. Environmental and Agricultural Modelling. Integrated Approaches for Policy Impact Assessment, 1st Edition ed. Springer, p. 325.

Brown, R.R., Deletic, A., Wong, T.H.F., 2015. How to catalyse collaboration. Nature 525, 315317.

Bruce, A., Lyall, C., Tait, J., Williams, R., 2004. Interdisciplinary integration in Europe: the case of the Fifth Framework programme. Futur. 36, 457-470.

Burgman, M., Fidler, F., Mcbride, M., Walshe, T., Wintle, B., 2006. Eliciting Expert Judgments: Literature Review. Australian Centre of Excellence for Risk Analysis, University of Melbourne, Melbourne, p. 70.

Canavese, D., Ortega, N.R.S., Queirós, M., 2014. The assessment of local sustainability using fuzzy logic: An expert opinion system to evaluate environmental sanitation in the Algarve region, Portugal. Ecol. Indicators 36, 711-718.

CFIR, 2004. Facilitating Interdisciplinary Research. Committee on Facilitating Interdisciplinary Research, National Academies Press, Washington D.C.

DEFRA, 2009. Further study to assess interactions between economics, husbandry \& welfare in large, extensively managed sheep flocks - AW1024. Final Report 2009. Department for Environment, Food and Rural Affairs, p. 27.

Eppler, M.J., Burkhard, R.A., 2007. Visual representations in knowledge management: framework and cases. Journal of Knowledge Management 11, 112-122.

Ewert, F., van Ittersum, M.K., Bezlepkina, I., Therond, O., Andersen, E., Belhouchette, H., Bockstaller, C., Brouwer, F., Heckelei, T., Janssen, S., Knapen, R., Kuiper, M., Louhichi, K., Olsson, J.A., Turpin, N., Wery, J., Wien, J.E., Wolf, J., 2009. A methodology for enhanced flexibility of integrated assessment in agriculture. Environ. Sci. Policy 12, 546-561.

Ewert, F., van Ittersum, M.K., Heckelei, T., Therond, O., Bezlepkina, I., Andersen, E., 2011. Scale changes and model linking methods for integrated assessment of agri-environmental systems. Agric. Ecosyst. Environ. 142, 6-17.

Flichman, G., Louhichi, K., Boisson, J.M., 2011. Modelling the Relationship Between Agriculture and the Environment Using Bio-Economic Models: Some Conceptual Issues, in: Flichman, G. (Ed.), Bio-Economic Models applied to Agricultural Systems. Springer Netherlands, pp. 3-14.

Goddard, P., 2011. Welfare assessment in sheep. Practice 33, 508-516.

Grix, J., 2002. Introducing Students to the Generic Terminology of Social Research. Politics 22, 175-186. 
Haapasaari, P., Kulmala, S., Kuikka, S., 2012. Growing into Interdisciplinarity: How to Converge Biology, Economics, and Social Science in Fisheries Research? Ecol. Soc. 17.

Harris, G., 2002. Integrated assessment and modelling: an essential way of doing science. Environ. Model. Softw. 17, 201-207.

Harvey, D.R., 2006. RELU Special Issue: Editorial Reflections. J. Agric. Econ. 57, 329-336.

Hasler, B., Romstad, E., Schou, J.S., Brandt, J., Vejre, H., 2003. The complexity of modelling farmers' provision of landscape goods ina multifunctinal setting. Advances in Ecological Sciences 15, 163-182.

Helming, K., Pérez-Soba, M., Tabbush, P., 2008. Sustainability Impact Assessment of Land Use Changes. Springer, Berlin, Heidelberg, p. 508.

Huang, M.-h., Chang, Y.-w., 2008. Characteristics of research output in social sciences and humanities: From a research evaluation perspective. Journal of the American Society for Information Science and Technology 59, 1819-1828.

Huber, R., Bugmann, H., Buttler, A., Rigling, A., 2013. Sustainable Land-use Practices in European Mountain Regions under Global Change: an Integrated Research Approach. Ecol. Soc. 18.

Jakobsen, C.H., McLaughlin, W.J., 2004. Communication in Ecosystem Management: A Case Study of Cross-Disciplinary Integration in the Assessment Phase of the Interior Columbia Basin Ecosystem Management Project. Environ. Manage. 33, 591-605.

Janssen, S., van Ittersum, M.K., 2007. Assessing farm innovations and responses to policies: A review of bio-economic farm models. Agric. Syst. 94, 622-636.

Janssen, S., Andersen, E., Athanasiadis, I.N., van Ittersum, M.K., 2009a. A database for integrated assessment of European agricultural systems. Environ. Sci. Policy 12, 573-587.

Janssen, S., Ewert, F., Li, H., Athanasiadis, I.N., Wien, J.J.F., Thérond, O., Knapen, M.J.R., Bezlepkina, I., Alkan-Olsson, J., Rizzoli, A.E., Belhouchette, H., Svensson, M., van Ittersum, M.K., 2009b. Defining assessment projects and scenarios for policy support: Use of ontology in Integrated Assessment and Modelling. Environ. Model. Softw. 24, 1491-1500.

Klein, J.T., 2004. Prospects for transdisciplinarity. Futur. 36, 512-526.

Klijn, J., 2003. On inter- or transdisciplinarity: inherent handicaps and some solutions?, in: Tress, B., Tress, G., van der Valk, A., Fry, G. (Eds.), Potential and Limitations of Interdisciplinary and Transdisciplinary Landscape Studies. Alterra Green World Research and Wageningen University, Wageningen, pp. pp 175-179. 
König, B., Diehl, K., Tscherning, K., Helming, K., 2013. A framework for structuring interdisciplinary research management. Res. Policy 42, 261-272.

Kragt, M.E., 2012. Bioeconomic modelling: Integrating economic and environmental systems?, in: Seppelt, R., Voinov, A.A., Lange, S., Bankamp, D. (Eds.), iEMSs2012; International Congress on Environmental Modelling and Software: Resources of a Limited Planet. International Environmental Modelling and Software Society, Leipzig, 1-5 July 2012.

Kragt, M.E., Newham, L.T.H., Bennett, J., Jakeman, A.J., 2011. An integrated approach to linking economic valuation and catchment modelling. Environ. Model. Softw. 26, 92-102.

Kragt, M.E., Pannell, D.J., Robertson, M.J., Thamo, T., 2012. Assessing costs of soil carbon sequestration by crop-livestock farmers in Western Australia. Agric. Syst. 112, 27-37.

Kragt, M.E., Robson, B.J., Macleod, C.J.A., 2013. Modellers' roles in structuring integrative research projects. Environ. Model. Softw. 39, 322-330.

Ledford, H., 2015. Team Science. Nature 525, 308-311.

Lowe, P., Phillipson, J., 2006. Reflexive Interdisciplinary Research: The Making of a Research Programme on the Rural Economy and Land Use. J. Agric. Econ. 57, 165-184.

McDonald, D., Bammer, G., Deane, P., 2009. Research Integration Using Dialogue Methods. ANU Press, Canberra.

Moran, D., Macleod, M., Wall, E., Eory, V., McVittie, A., Barnes, A., Rees, R., Topp, C.F.E., Moxey, A., 2011. Marginal Abatement Cost Curves for UK Agricultural Greenhouse Gas Emissions. J. Agric. Econ. 62, 93-118.

Moxey, A., White, B., 1998. NELUP: Some Reflections on Undertaking and Reporting Interdisciplinary River Catchment Modelling. J. Environ. Plan. Manage. 41, 397-402.

Murray, J.V., Goldizen, A.W., O'Leary, R.A., McAlpine, C.A., Possingham, H.P., Choy, S.L., 2009. How useful is expert opinion for predicting the distribution of a species within and beyond the region of expertise? A case study using brush-tailed rock-wallabies Petrogale penicillata. Journal of Applied Ecology 46, 842-851.

Nooteboom, B., 2000. Learning by Interaction: Absorptive Capacity, Cognitive Distance and Governance. J. Manage. Governance 4, 69-92.

Norgaard, R.B., 1992. Coordinating disciplinary and organizational ways of knowing. Agric. Ecosyst. Environ. 42, 205-216.

Nutbeam, D., 2013. Students can be interdisciplinary too, Higher Education Network. The Guardian, 12 August 2013. 
Pannell, D.J., Marshall, G.R., Barr, N., Curtis, A., Vanclay, F., Wilkinson, R., 2006. Understanding and promoting adoption of conservation practices by rural landholders. Aust. J. Exp. Agric. 46, 1407-1424.

Perry, G.M., 2012. WAEA Presidential Address Deciding Where to Publish: Some Observations on Journal Impact Factor and Article Influence Score. J. Agric. Resour. Econ. 37, 335-348.

Rafols, I., Leydesdorff, L., O’Hare, A., Nightingale, P., Stirling, A., 2012. How journal rankings can suppress interdisciplinary research: A comparison between Innovation Studies and Business \& Management. Res. Policy 41, 1262-1282.

Reidsma, P., König, H., Feng, S., Bezlepkina, I., Nesheim, I., Bonin, M., Sghaier, M., Purushothaman, S., Sieber, S., van Ittersum, M.K., Brouwer, F., 2011. Methods and tools for integrated assessment of land use policies on sustainable development in developing countries. Land Use Policy 28, 604-617.

Rossini, F.A., Porter, A.L., 1979. Frameworks for integrating interdisciplinary research. Res. Policy 8, 70-79.

Rotmans, J., van Asselt, M., 1996. Integrated assessment: A growing child on its way to maturity. Clim. Chang. 34, 327-336.

Stott, A.W., Vosough Ahmadi, B., Dwyer, C.M., Kupiec, B., Morgan-Davies, C., Milne, C.E., Ringrose, S., Goddard, P., Phillips, K., Waterhouse, A., 2012. Interactions between profit and welfare on extensive sheep farms. Animal Welfare 21, 57-64.

Tanure, S., Nabinger, C., Becker, J.L., 2013. Bioeconomic model of decision support system for farm management. Part I: Systemic conceptual modeling. Agric. Syst. 115, 104-116.

Tiffin, R., Traill, W.B., Mortimer, S., 2006. Food Choice in an Interdisciplinary Context. J. Agric. Econ. 57, 213-220.

Tress, B., Tress, G., Fry, G., 2003. Potential and limitations of interdisciplinary and transdisciplinary landscape studies, in: Tress, B., Tress, G., van der Valk, A., Fry, G. (Eds.), Potential and Limitations of Interdisciplinary and Transdisciplinary Landscape Studies. Alterra Green World Research and Wageningen University, Wageningen, pp. pp 182-192.

Tress, G., Tress, B., Fry, G., 2007. Analysis of the barriers to integration in landscape research projects. Land Use Policy 24, 374-385.

van Ittersum, M., 2009. Integration across disciplines: the lessons learnt from the integrated project SEAMLESS. Aspects of Applied Biology 93, 55-60.

van Ittersum, M.K., Ewert, F., Heckelei, T., Wery, J., Alkan Olsson, J., Andersen, E., Bezlepkina, I., Brouwer, F., Donatelli, M., Flichman, G., Olsson, L., Rizzoli, A.E., van der Wal, T., Wien, J.E., Wolf, 
J., 2008. Integrated assessment of agricultural systems - A component-based framework for the European Union (SEAMLESS). Agric. Syst. 96, 150-165.

van Rijnsoever, F.J., Hessels, L.K., 2011. Factors associated with disciplinary and interdisciplinary research collaboration. Res. Policy 40, 463-472.

Volk, M., Ewert, F., 2011. Scaling methods in integrated assessment of agricultural systemsState-of-the-art and future directions. Agric. Ecosyst. Environ. 142, 1-5.

Wam, H.K., 2010. Economists, time to team up with the ecologists! Ecol. Econ. 69, 675-579.

Wang, Q.J., Robertson, D.E., Haines, C.L., 2009. A Bayesian network approach to knowledge integration and representation of farm irrigation: Model development. Water Resour. Res. 45.

Weersink, A., Jeffrey, S., Pannell, D., 2002. Farm-Level Modeling for Bigger Issues. Rev. Agric. Econ. 24, 123-140.

Williams, H., 1996. The essence of managing groups and teams. Prentice Hall, Hemel Hempstead. 


\section{Box 1: Example lessons for more successful interdisciplinary bio-economic modelling projects}

\section{Time commitments}

- Recognise the need to establish personal and stable collaborative relationships

- Don't underestimate the time and resources required in an interdisciplinary project (including when preparing funding proposals)

- Invest time at the start to develop a shared vision about the overall project goal and objectives

- Organise an inception meeting with all project participants to align expectations

Communication

- Regular (face-to-face) communication and feedback are key

- Shared ontologies are useful to clarify disciplinary terminologies

- Use 'plain English' rather than disciplinary jargon

- Co-construct visual communication aids to overcome language differences

13 Data-handling and research protocols

- Develop conceptual frameworks and shared collaborative ontologies to agree on data format and scales

- Communicate expectations regarding data and research approaches

Train research 'integrators'

- Include interdisciplinary research skills in postgraduate curricula

- Enable interdisciplinary PhD programs

Academic recognition

- Institutions can introduce key performance indicators that reward research collaboration and impact

- Funding agencies can introduce initiatives that stimulate cross-disciplinary research

- Editorial and reviewing policies can be altered to encourage greater acceptance of high-quality interdisciplinary research 


\section{Box 2: A case study example of interdisciplinary communication}

The strategy employed by the authorship team for Pannell et al. (2006) illustrates a range of useful methods for dealing with the communications challenges of interdisciplinary research. The team consisted of two economists, three rural sociologists and one social psychologist. An initial face-to-face meeting was held in 2001 to discuss the project scope and aims. At the meeting, it was apparent that there were major differences between team members in conceptual frameworks, perspectives on the project, and language. These differences greatly hampered efforts to reach agreement amongst the team. It was decided that, prior to commencing work on the intended project, the team would attempt to prepare a document describing a conceptual framework that combined elements from each of the participating disciplines, and defined and used a set of terms that would be acceptable to all participants (similar to the use of ontologies recommended in Section 3.2).

One team member with a broad perspective (an economist in this case) was assigned the task of leading the preparation of the document. After seeking input from all team members about content for the document, the leader prepared an initial draft, drawing together the various contributions as best he could. The initial draft fell well short of satisfying all participants. There followed several rounds of feedback, email discussion amongst the team about how to deal with the feedback, and revision to the document by the leader. This proved to be a rather protracted and time consuming process, but eventually, after two years, a document was completed that all team members were reasonably happy with. The duration of this stage of the process indicates how difficult it was to resolve the conceptual and communication issues.

Only then did the originally planned project commence. The team found that the time invested in the original process of producing a consensus conceptual framework and common language paid off handsomely. Communication, mutual understanding and mutual respect were strong throughout the remaining process. Indeed, the project itself proceeded much more smoothly than had the original teambuilding process. The view of team members was that this strategy was crucial to the successful completion of the paper, which subsequently has been highly cited and the inspiration for a number of additional initiatives. 